\title{
Urban-rural Relationships in Feeding Metropolis: a Case Study in Ljubljana Metropolitan Area

\author{
Guido Sali ${ }^{1, a}$, Stefano Corsi ${ }^{2, b}$ Federica Monaco $^{1, c}$, Chiara Mazzocchi1,d, \\ Matjaž Glavan ${ }^{3, e}$ and Marina Pintar ${ }^{3, f}$
}

${ }^{1}$ DiSAA, University of Milan, via G. Celoria, 220133 Milano, Italy

${ }^{2}$ DEMM, University of Milan, via G. Celoria, 220133 Milano, Italy

${ }^{3}$ University of Ljubljana, Biotechnical Faculty, Jamnikareva 1011000 Ljubljana, Slovenia

aguido.sali@unimi.it, b stefano.corsi@unimi.it, cfederica.monaco@unimi.it, dchiara.mazzocchi1@unimi.it, ematjaz.glavan@bf.uni-lj.si, ' marina.pintar@bf.uni-lj.si

\section{Keywords: Metropolitan Area, Urban Core, Food Balance}

\begin{abstract}
Metropolitan areas are characterized by the coexistence of a urban core insisting on natural resources of surrounding rural areas, strictly linked to the former. Inevitably, increasing urbanization and its consequences affect the model of urban development, which then needs to deal with the challenge of sustainability, also aiming to reduce pressures on resources and on supplying capacities of rural agricultural systems in providing food to urban zones, traditionally lacking. It then becomes important to deepen the possibility for the dense core to be supplied through proximity agriculture, able to recreate and improve synergic connections between urban and rural spheres.

The paper aims to study the relationships among them for feeding the metropolis, adopting a methodology for the spatial definition of urban centre in metropolitan area and the assessment of its food balance, in order to identify the potentialities of local and proximity agriculture and provide a first evaluation for the possibility to match urban development and production potential. Identified tools are applied to Ljubljana metropolitan area.
\end{abstract}

\section{Introduction}

International studies have identified and provided a spatial delimitation of metropolitan regions [1] and Functional Urban Areas [2], according to morphological, economic and functional parameters. These methodologies agree on the evidence that around a central core, generally a single metropolis, gravitate further areas, variously integrated to it. Two main and distinct components of the wider metropolitan system then coexist and interact: a higher-dense urban zone and less dense areas, typically the rural ones, closely related to the former [3]. Relative proportions and relations between them contribute to characterize the area as monocentric or polycentric, and to spatially describe its internal structure, as recently pointed out by [4] with the "Rural-Urban Region". In the main urban core the most of the population is concentrated. If currently $72.8 \%$ of European population lives in urban areas, it is estimated that by 2020 this percentage will exceed $75 \%$, and in 2050 will reach almost $85 \%$ [5]. Such an increase is a well-known phenomenon that determines a parallel augmentation in population needs and in demand for resources, changing the "metabolism" of a city $[6,7]$. The conversion of agricultural into build up land is particularly to be found on peri-urban areas that are growing four times faster than urban ones, at a rate which, if continued, would double their extent in the EU-27 of 48,000 $\mathrm{km}^{2}$ in 30-50 years [8]; a stronger urbanization leads to a higher soil consumption, required by residential and economic development, exacerbating conflicts in land use, diminishment of arable land [9] and productive potential of a specific territory.

According to [10], a city is not able to feed itself with its own resources. This capacity would instead come from the surrounding rural areas and their supplying capacities, which in turn are strongly threatened and affected by urbanization; however in urban contexts of western Europe only $20 \%$ of the agricultural production is marketed locally [11]. Moreover, global market supply is often inadequate for food requirement, as evidenced by issues related to satisfying food demand, security and accessibility [12] and meeting environmental sustainability. 
Deepen existing dynamics between urban and rural areas allow to define opportunities and/or necessities for the city in supplying from proximate areas. This would also evidence the possibility to potentiate the local and closer component, even through proximity agriculture, while taking into account urban development conditions that would further impact on agricultural and rural system.

In such a context the assessment of food balance as a comparison between demand and supply in a specific territory, could represent a first instrument to evaluate its capacities to be fed within proximate areas. If on one hand the foodshed concept [13], considers the connection between food and its source, most of its analyses [14,15] are generally based on a specific area defined by administrative boundaries or other starting assumptions, without any connection with actual or potential food demand. In order to spatially delineate and analyze their dimensions and estimate productive and local self-sufficiency capacities of a metropolis, a methodological approach is proposed and applied to the case study area of Ljubljana metropolitan region.

\section{Case study area}

Ljubljana is the capital of the Republic of Slovenia, administratively a part of the Municipality of Ljubljana (MOL) and in broader terms, a part of the Ljubljana metropolitan region (LMR). MOL, covering an area of $275 \mathrm{~km}^{2}$, encompasses $1.36 \%$ of Slovenian territory $\left(20,273 \mathrm{~km}^{2}\right)$ and has 286,994 inhabitants (2013), who make up for $13.9 \%$ of population of Slovenia $(2,060,663)$.

The dense core of Ljubljana is integrating with other municipalities into Ljubljana Urban Region (LUR) encompassing 26 municipalities with a total of over 500,000 residents or $25 \%$ of all population of Slovenia. LUR's boundaries correspond to the boundaries of central Slovenian statistical region, representing $12.6 \%\left(2,555 \mathrm{~km}^{2}\right)$ of total Slovenian territory. MOL has the highest density of population in Slovenia, is economically the best developed and has the highest index of the standard of living. MOL plays a key role in the entire area of LUR and LMR, connecting the region into an integral whole with its administrative and economic power, traffic ways and daily migration of labour.

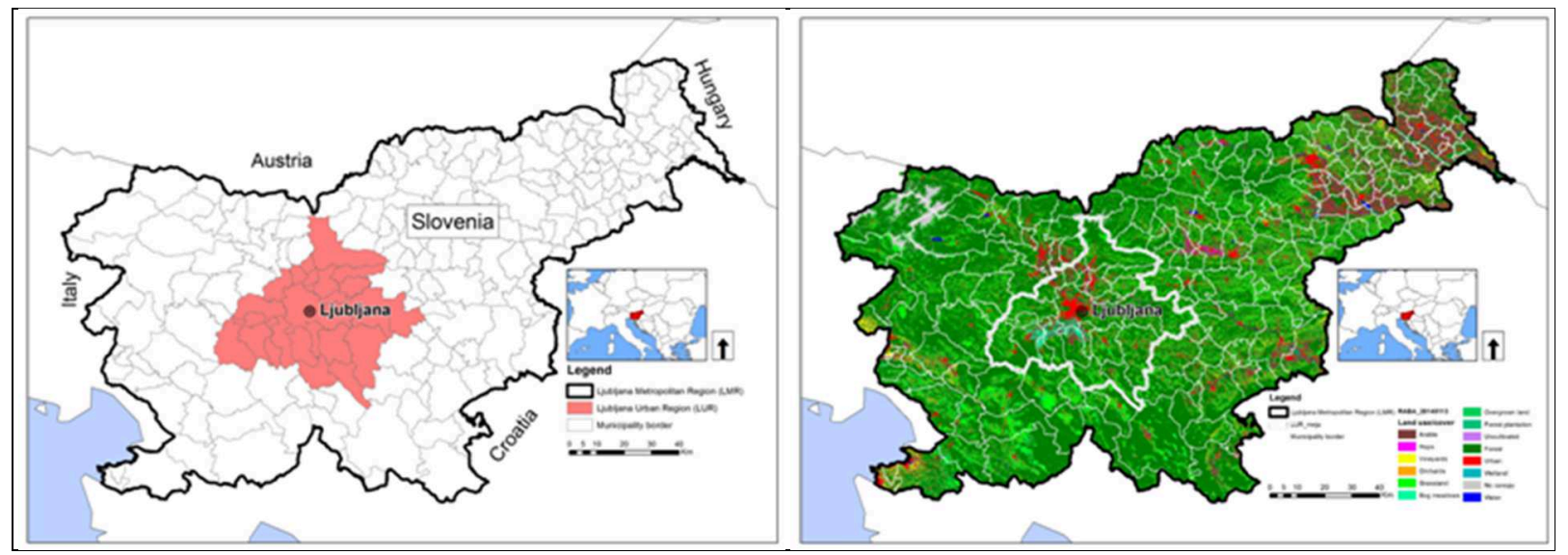

Figure 1: Ljubljana Metropolitan (LMR) and Urban Region (LUR) and land use/cover map.

\section{Methodology of analysis}

In order to delineate a "dense core" within metropolitan area where the most of food demand is generated, an operative model has been identified; it refers to a spatial autocorrelation, based on LISA (Local Indicators for Spatial Association) approach [16]. It allows to spatially weight territorial variables considered representative for a phenomenon and, being supported by the GIS-based software GeoDa, it returns results graphically. The analysis has been carried out at LAU2-level, taking into account population density as the only input variable. Result has allowed to delineate the most densely-populated area as the set of clusters that include high-dense and low-dense municipalities bordering in turn to other ones densely populated. 
Both in metropolitan region and in the dense core thus identified, food demand and supply have been analysed from a quantitative point of view [17]. In particular, food consumption has been assumed as a proxy for food demand, starting from data provided by national statistics [18]. As heterogeneous products, consumptions have been converted in total area of wheat they correspond to, and then compared to total arable land [19], if it would be entirely devoted to wheat. Thus, a simplified food balance, meant as the difference between supplied and demanded areas, has been evaluated, along with the quantification of food self-sufficiency. The ratio between supply and demand expresses, in fact, the extent of a territorial unit to meet its own food needs and its spatial analysis provides indications about the possibility to satisfy urban demand through proximity agriculture.

\section{Main results}

Spatial analysis has returned a cluster map where is evident the main dense core around Ljubljana, separated from the rest of the National context, that reveals the mono-centric structure of LUR. These results are consistent with the features of the entire region. In fact, all denser areas (coloured in red) represent the four largest cities in Slovenia, with Ljubljana in the centre being the largest and the most densely populated. When Ljubljana became the capital city in the 1991, the neighbouring municipalities developed fast with establishment of the economic zones. This attracted new migrants from all over the Metropolitan region rising population density in the former rural suburb. The identified core actually represents a high-densely populated zone and has territorial features quite different from those of the wider metropolitan area (table 1). However, to better understand these disparities, food supply and demand are to be analysed.

Table 1: Main features of considered areas

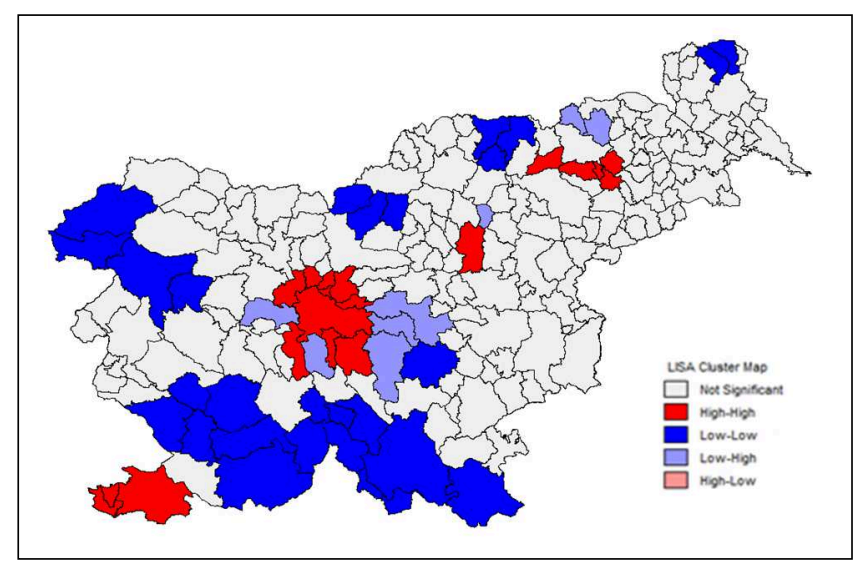

\begin{tabular}{|lrrr|}
\hline & LMR & LUR & \multicolumn{1}{c|}{$\begin{array}{c}\text { Dense } \\
\text { core }\end{array}$} \\
\hline $\begin{array}{l}\text { Municipalities } \\
{[\mathrm{n} .]}\end{array}$ & 210 & 26 & 15 \\
\hline $\begin{array}{l}\text { Population } \\
{[\text { inhabitants }]}\end{array}$ & $2,050,189$ & 533,213 & 440,227 \\
\hline $\begin{array}{l}\text { Area } \\
{\left[\mathrm{km}^{2}\right]}\end{array}$ & 20,172 & 2,544 & 1,541 \\
\hline $\begin{array}{l}\text { Density } \\
{\left[\text { people per } \mathrm{km}^{2}\right]}\end{array}$ & 102 & 210 & 286 \\
\hline $\begin{array}{l}\text { Arable land } \\
{[\text { ha] }]}\end{array}$ & 183,826 & 17,834 & 16,044 \\
\hline
\end{tabular}

Figure 2: Denser areas within LMR

Food demand at municipal level (figs. 3 and 4) is strictly connected with the numerousness of population. In all of the municipalities with high food demand ( $>1000$ ha) bigger cities are located, with favourable natural (lowlands, water) and economic (economic centres, transport connections) conditions. This encourages immigration from rural to urban areas, which in turn reduces food demand in rural areas and increases it in the urban centres. 


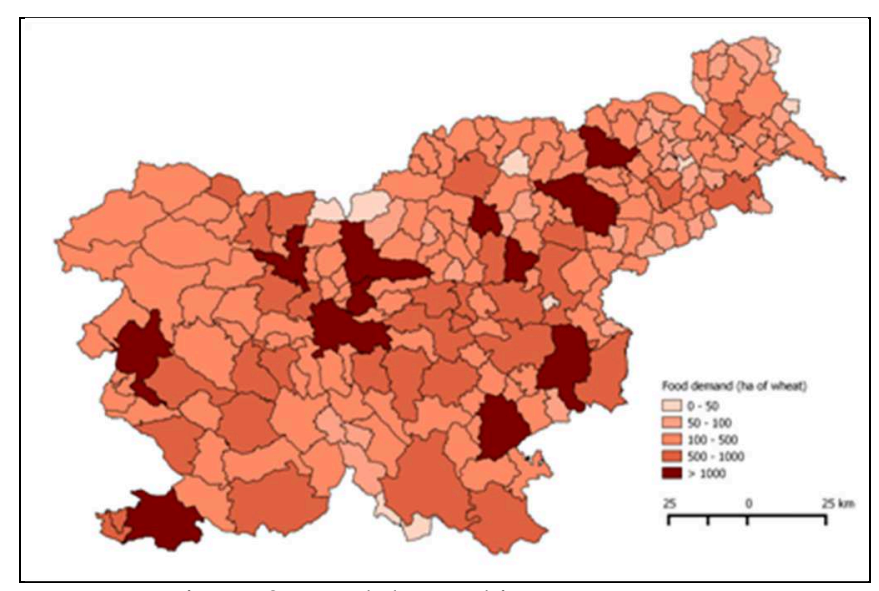

Figure 3: Food demand in LMR

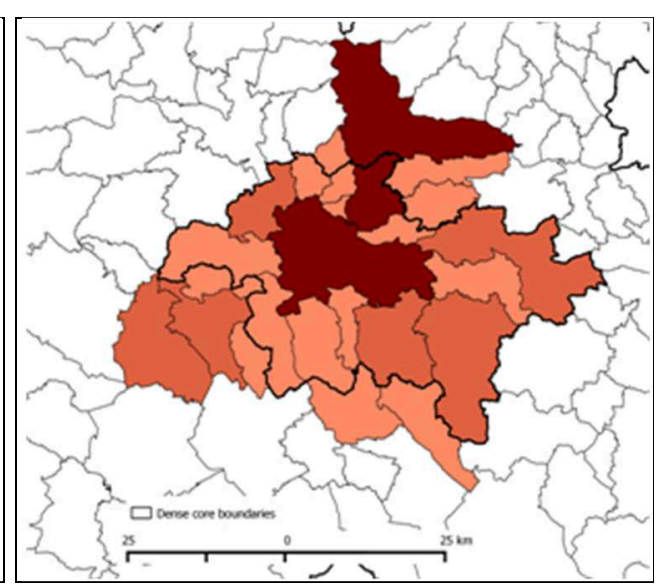

Figure 4: Food demand in LUR

Due to the aforementioned favourable conditions, a higher availability of arable land on local level corresponds more precisely to these municipalities, as they majorly lie on alluvial plains or in Pannonia flatlands (figs. 5 and 6). However, the hectares of agricultural land are nominally smaller in smaller municipalities, although they are almost entirely agricultural, while certain larger municipalities have fewer hectares for food supply than the others, which correlates to the fact that great proportion of their territory is devoted to protected zones and forests (Dinaric Karst Forests in the South) or mountains (Alps in the North), not suited to arable land.

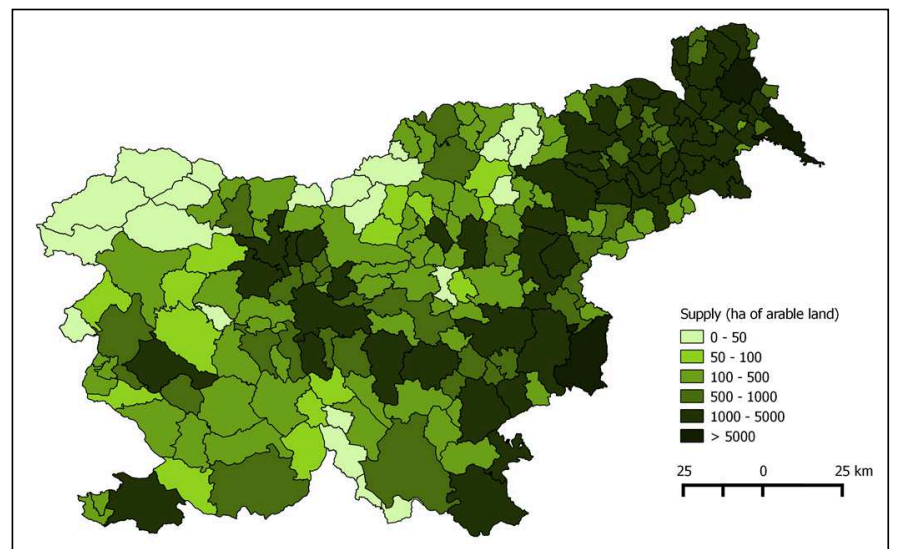

Figure 5: Food supply in LMR

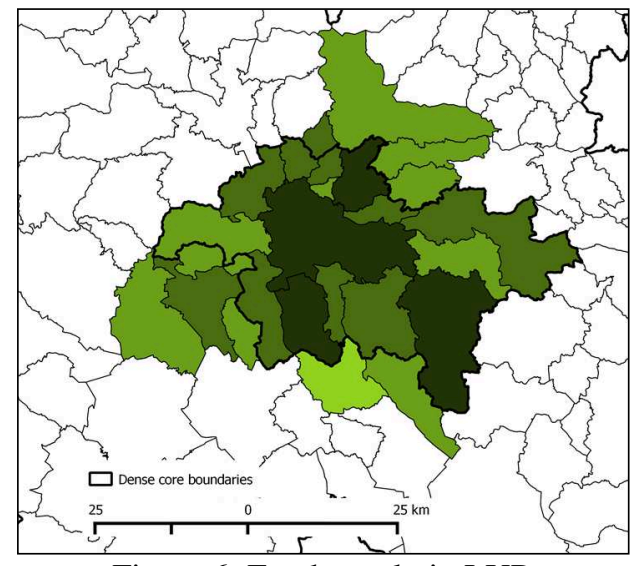

Figure 6: Food supply in LUR

On these bases, it seems that most of the municipalities and LMR as a whole have the chance to be potentially supplied within their boundaries (fig. 7). Self-sufficiency in LMR is very high and equals 222\%. However, certain cities (especially the largest two Ljubljana and Maribor) and areas in mountainous and mostly forested regions are faced with less than 50\% food self-sufficiency: agriculture in mountainous areas is manly concentrated on cattle and dairy production with grain import from other areas and on forestry, while in Western hilly Mediterranean areas grape for vine production predominates. Inside the LUR, where demand is met for $83 \%$, MOL, though a quite high amount of supply area (more than 2,700 ha of arable land), is the municipality that shows the lowest productive deficit (fig. 8), since its capacity to satisfy population demand is about $25 \%$. Being placed in a region (LMR) and surrounded by municipalities (LUR) with higher food self-sufficiencies, it however may find the lacking quantities in its proximity, in the maximum distance of approximately $25 \mathrm{~km}$. 


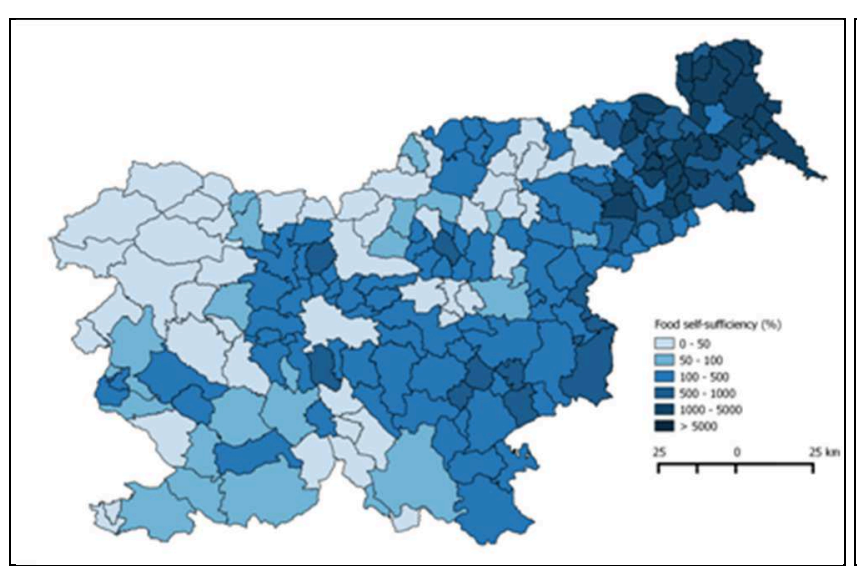

Figure 7: Food self-sufficiency in LMR

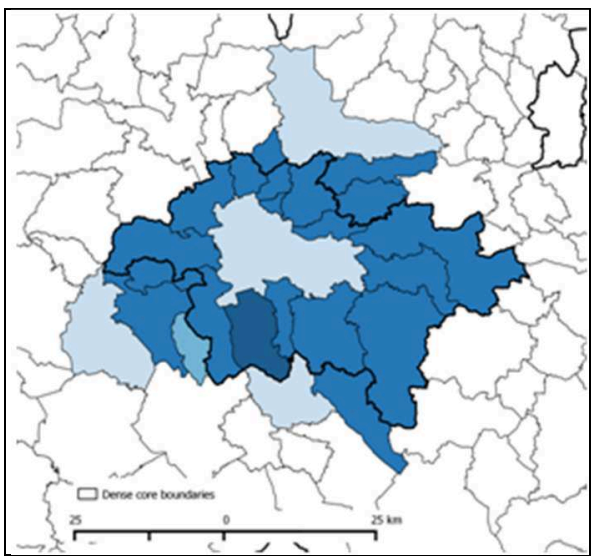

Figure 8: Food self-sufficiency in LUR

\section{Concluding remarks}

Carried analyses, even though including several approximations, give good and consistent results with the case study context. They show that in this region there would be different conditions of food balance, according to the scale of analysis. More in detail, LMR shows overall very good production potential; the availability of such a large supply is mostly reflected on a municipal level, as well, due to relatively high amounts of arable land, even in the denser core; we can then hypothesize that a further urban development, in many cases limited by natural constraints, would not affect negatively the overall food balance of the LMR, nor significantly that of the LUR, but rather food capacities in the Municipality of Ljubljana.

The possibility for an area to be supplied by proximity agriculture could be a determining factor for the development of local strategies and Local Agri-food Systems that can also play a role to contrast, or strongly balance, urban sprawl and its effects on rural areas. These systems need to be governed, so that their potential of meeting food demand and supply, can be suitably exploited and managed. For that purpose, several governance tools could be established at a policy level, also in order to improve the involvement of local communities and push for the creation and intensification of synergic relationships between urban and rural areas, trying, at the same time, to preserve their own peculiar characteristics.

\section{Acknowledgements}

This work has been carried out within planned activities of the EU-FP7 project - 312185 FOODMETRES (Food planning and innovation for sustainable metropolitan regions).

\section{References}

[1]OECD: Redefining “urban": a new way to measure metropolitan areas (OECD Publishing, 2012). http://dx.doi.org/10.1787/9789264174108-en

[2]ESPON, Final Report ESPON 2006 INTERREG III Programme, Information on http://www.espon.eu/export/sites/default/Documents/Programme/ESPON2006Programme/Annu alReports/espon_2006_final_implementation_report_29.06.2009.pdf. (Accessed 22 ${ }^{\text {nd }}$ July 2013)

[3]FAO. Food, Agriculture and Cities. Challenges of food and nutrition security, agriculture and ecosystem management in an urbanizing world. FAO Food for the cities multi-disciplinary initiative position paper, (2011)

[4]I. Zasada, W. Loibl, R. Berges, K. Steinnocher, M. Koestl, A. Piorr and A. Werner: Rural-Urban Regions: a spatial approach to define Urban-Rural relationships in Europe in: Peri-urban futures: scenarios and models for land use change in Europe; Nilsson, Pauleit, Bell, Aalbers, Nielsen eds. (2013) 
[5]United Nation Department of Economic and Social Affairs (UNDESA), Population Division: World Population Prospects: The 2011 Revision. Information on http://esa.un.org/unup/Documentation/final-report.htm/, Accessed $27^{\text {th }}$ July 2013

[6] A. Wolman: The metabolism of cities. Scientific American, 213(3),179-190. Scientific American, 213(3) (1965), pp. 179-190

[7]C. A. Kennedy, J. Cuddihy and J. Engel Yan (2007). The changing metabolism of cities. Journal of Industrial Ecology Vol. 11(2) (2007), pp. 43-59

[8]A. Piorr, K. Muller and I. Tosics: Peri-urbanisation in Europe: towards a European policy to sustain urban-rural futures. Synthesis report. Academic Books, Frederiksberg, Copenhagen, Denmark (2011)

[9]L. R. Oldeman, R.T.A. Hakkeling and W.G. Sombroek: World map of the status of human-induced soil degradation: global assessment of soil degradation (International Soil Reference and information Centre, Wageningen, The Netherlands, 1999)

[10] F. Asher, Les nouveaux principes de l'urbanisme, la fin des villes n'est pas à l'ordre du jour in: Géocarrefour. Vol. 76 n4, 2001. Quel periurbain aujourd'hui. p. 348. Prost Brigitte

[11] Committe of the Regions. Opinion of the Committee of the Regions on 'Local food systems' (outlook opinion). Official journal of the European Union, 2011/C 104/01

[12] A. Getz: Urban foodsheds. The Permaculture Activist (October): 26-27 (1991)

[13] N. Alexandros and J. Briunsma: World agriculture towards 2030/2050, ESA working paper 12-03. Agriculture Economics Development Division, FAO, 2012. Information on http://www.fao.org/economic/esa. (Accessed $31^{\text {st }}$ January 2014)

[14] G. Billen, S. Barles, and J. Garnier: The food-print of Paris: long-term reconstruction of the nitrogen flows imported into the city from its rural hinterland, Reg Environ Change. 9 (2009), pp. $13-24$

[15] C. J. Peters, N.L. Bills, A.J. Lembo, J.L. Wilkins and G.W. Fick: Mapping potential foodsheds in New York State : a spatial model for evaluating the capacity to localize food production, Renewable Agriculture and Food Systems. 24 (2009), pp. 72-84

[16] L. Anselin: Local indicators of Spatial Analysis - LISA, Geographical analysis, 27. Ohio State University Press (1995)

[17] G. Sali, S. Corsi, F. Monaco and C. Mazzocchi: Le dimensioni del bilancio alimentare nel contesto metropolitano milanese, Industrie alimentari. 542, Gennaio 2014, pp. 24-29

[18] STAT (2014a). The average allocated assets of households, Slovenia, annually. Statistical Office of the Republic of Slovenia. Information on http://www.stat.si/ (Accessed $9^{\text {th }}$ January 2014).

[19] STAT (2014b). The average yield (t/ha) of major crops by statistical regions, Slovenia, annually. Statistical Office of the Republic of Slovenia. Information on http://www.stat.si/ (Accessed $9^{\text {th }}$ January 2014). 